\title{
Farklı uygulamaların plastik serada saksıda yetiştirilen bazı şeftali çeşitlerinin erkencilik ve meyve özellikleri üzerine etkilerinin araştırılması
}

\section{Investigation of the effects of different applications on earliness and fruit properties of some peach cultivars grown in pots in plastic greenhouse}

\author{
Sara DEMIRAL ${ }^{1}$ (D), Salih ÜLGER ${ }^{2}$ (i) \\ ${ }^{1}$ Tarım İl Müdürlüğü, Antalya \\ ${ }^{2}$ Akdeniz Üniversitesi, Ziraat Fakültesi, Bahçe Bitkileri Bölümü, 07070, Antalya \\ Sorumlu yazar (Corresponding author): S. Ülger, e-posta (e-mail): ulger@akdeniz.edu.tr \\ Yazar(lar)e-posta (Author e-mail): sarademiral@gmail.com
}

\section{MAKALE BİLGİSİ}

Alınış tarihi 26 Şubat 2020

Düzeltilme tarihi 30 Aralık 2020

Kabul tarihi 31 Aralık 2020

\section{Anahtar Kelimeler:}

Şeftali

Erkencilik

Saksıda yetiştiricilik

\section{ÖZ}

Bu çalışmada, Antalya koşullarında erkencilik elde etmek amacıyla plastik serada saksılarda yetiştirilen 2 yaşındaki 'Early Maycrest', 'Francois' ve 'Maycrest' şeftali çeşitlerine ocak ayı ortasında 2 y1l süreyle kontrol (saf su), \%2.5 Dormex, 200 ppm GA 3 ve soğukta bekletme $\left(5^{\circ} \mathrm{C}\right.$ 'de 30 gün) uygulamaları yapılmıştır. Uygulamalardan 30 gün sonra dış ortamda bulunan bitkiler plastik seraya tasınmıs ve hasat zamanına kadar plastik serada bekletilmişlerdir. Meyve hasadından sonra, bitkiler \%40 gölge sağlayan ağ altına alınmışlardır. Çalışma süresince bitkilerde bazı fenolojik ve pomolojik özellikler incelenmiştir. Uygulamalar tomurcuklarda uyanmayı kontrole göre 11-25 gün, çiçeklenmeyi 13-16 gün erkene almış ve en erken uyanma ve çiçeklenme \%2.5 Dormex uygulanan bitkilerde görülmüştür. Uygulamalar hasadı kontrole göre 2 gün ('Maycrest', soğukta bekletme) ile 10 gün ('Early Maycrest', \%2.5 Dormex ve 200 ppm GA 3 ) erkene almıştır. İlk hasat 14 Mayıs'ta 200 ppm GA 3 uygulanan 'Francoise' çeşidinde yapılmıştır. Uygulamalar her üç çeşitte de verimi kontrole göre artırmış ve ortalama en fazla verimler 2305 ve $2301 \mathrm{~g}^{\text {ağaç }}{ }^{-1}$ ile sırasıyla $\% 2.5$ Dormex uygulanmış ve soğukta bekletilmiş 'Francoise' çeşidinden elde edilmiştir. Uygulamalar bitkilerin yaprak döküm tarihleri üzerine etkili olmamıştır. Uygulamalar kontrola göre meyvelerin ağırlığını, boyunu, enini, çekirdek ağırlığını ve meyve eti/çekirdek oranını artırmıș, ancak suda çözünebilir kuru madde (SÇKM) ve titre edilebilir asit (TEA) miktarı üzerine önemli etki yapmamıştır. Uygulamalar meyve kabuğu canlılığı ve parlaklığı üzerine önemli etki göstermezken, meyve kabuğunda kırmızı rengi artırmıștır. Araștırma sonuçları, seçilen șeftali çeșitlerinin Antalya koşullarında soğuklama bakımından sorununun olmadığını ve plastik serada yetiştirmenin dış ortama göre çeşitlere bağlı olarak 2-10 gün erkencilik sağladığını ortaya çıkarmıştır.

\section{ARTICLE INFO}

Received 26 February 2020

Received in revised form 30 December 2020

Accepted 31 December 2020

\section{Keywords:}

Peach

Earliness

Container growing

\section{ABSTRACT}

This study was conducted to examine the earliness of 'Early Maycrest', 'Francoise' and 'Maycrest' peach cultivars grown in pots in plastic greenhouse under Antalya ecological conditions. Pure water as control, 2.5\% Dormex, 200 ppm GA 3 and artificial chilling $\left(30\right.$ days at $\left.5^{\circ} \mathrm{C}\right)$ were applied on 2years-old cultivars in mid January for two years. The plants were moved to the plastic greenhouse 30 days after the treatment and kept there until harvest. Some phenological and pomological properties of the plants during the vegetation period were examined. Treated plants showed bud burst 11-25 days earlier and flowers were observed 13-16 earlier comparing the control, and the earliest bud burst and flowers were observed with $2.5 \%$ Dormex treatment. The first harvest was achieved with 'Francois' cultivar in $200 \mathrm{ppm} \mathrm{GA}$ treated plants on $14^{\text {th }}$ May. The applications increased the yield in all three cultivars according to the control, and the average maximum yields were obtained from the 'Francois' cultivar in 2.5\% Dormex applied and artificial chilled plants with 2305 and $2301 \mathrm{~g}$ tree $^{-1}$, respectively. The weight, height, width, kernel weight and flesh/kernel ratio of fruits were also increased in treated plants compare to control. While not only the soluble solids content (SSC) and titratable acidity (TA) were not significantly different, but also the viability and luster of the peel were not significantly different. However, the red color was increased in the peel. The results showed that the mentioned cultivars do not face any problems in terms of chilling in Antalya and growing them in a plastic greenhouse provide 2-10 days of earliness depending on the cultivars. 


\section{Giriş}

Akdeniz sahil kuşağında sert çekirdekli meyvelerin erkencilik sağlamak amacıyla örtüaltında yetiştiriciliği son yıllarda artış göstermiştir. Bu amaçla şeftali, nektarin, erik, kayısı gibi meyveler sera içerisine toprağa dikim şeklinde veya saksıda yetiştirilmektedir. Saksıda yetiştirilen sert çekirdekliler içerisinde şeftaliye budama ile istenilen şeklin verilebilmesi önemli avantajıdır.

Vejetatif ve çiçek tomurcuğu gelişim dönemi üretim periyodunun zamanlaması açısından çok önemlidir. Vejetatif tomurcuklar normalde çiçek tomurcuklarından daha fazla soğuklamaya ihtiyaç duyarlar ve bunlar yüksek sıcaklıklara farklı tepki verirler. Kökten gelen su ve besin maddeleri, karbonhidratlar ve hormonların alımında çiçek ve vejetatif tomurcuklar arasında bir rekabet vardır. Bu rekabet çiçek ve küçük meyve dökümlerini etkileyebilmektedir. Çiçek tomurcukları meyve tutumundan sonra gelişebilmesi için doğal serin iklim koşullarında her zaman vejetatif tomurcuklardan daha hızlı gelişirler. Bununla birlikte, sıcak iklim koşullarında vejetatif ve çiçek tomurcukları eşzamanlı olarak gelişme gösterebilmektedir. $\mathrm{Bu}$ durum serada şeftali ve nektarin yetiştiriciliğinde dikkat edici şekilde görülmekte ve bunun sonucunda düşük meyve tutumu ile fazla meyve dökümleri olmaktadır. Soğuklamanın eksikliğinden kaynaklanan bu sorun bazı kimyasal uygulamalarıyla ortadan kaldırılabilmektedir (Erez ve ark. 2000).

Sicilya-İtalya'da kalite ve erkenciliği artırmak amacıyla örtüaltına 4 şeftali ve 2 nektarin çeşidi 1.40 x $0.90 \mathrm{~m}$ mesafelerde dikilmiş ve farklı budama sistemleri uygulanmıştır. Florida orijinli 'Maravilha', 'San Pedro' ve 'Sunred' çeşitleri budama uygulamalarına iyi sonuçlar vermiştir. Beyaz etli şeftali 'Maravilha' nisan sonunda ve sarı renkli nektarin 'San Pedro' mayıs' 1 ilk haftasında hasat edilmiştir (Bellini ve ark. 1992).

Hasat periyodundan önce şeftali ve nektarinlerin hasad edilmesi üründen daha fazla gelir alınmasını sağlamaktadır. Özellikle şeftali ve nektarinlerin mart ayı sonlarında ve nisan ayı boyunca dünya pazarlarına arzı çok düşüktür. Serada erkenci şeftali ve nektarin yetiştirmek amacıyla yapılan çalışmalarda iklim koşullarına bağlı olarak farklı sorunlar ortaya çıkmıştır. Meyvelerde olgunlaşmayı erkene almak ve meyve özelliklerini iyileştirmek için doğal soğutma birikiminin arttırılması, eksik soğuklamanın bir kısmının bazı kimyasallarla karşılanması, farklı yapıda polietilen örtü kullanma gibi uygulamalar yapılmıştır. $\mathrm{Bu}$ araştırmalar sonucunda İsrail koşullarında mart ayı sonunda yüksek kaliteli şeftali ve nektarin meyveleri hasat edilmiştir (Erez ve ark. 1998).

Sicilya'nın Güney-Doğu sahillerinde 'GF677' anacı üzerine aş11 5 şeftali ve 1 nektarin çeşidi açıkta ve örtüaltında $2 \times 1 \mathrm{~m}$ mesafelerde yetiştirilmiştir. Dört yıllık sonuçlara göre erkenci çeşitler 'Flordaprince' ve 'Maravilha' olurken, 'Maravilha' ve 'San Pedro' çeşitleri verimli olarak belirlenmiştir (Bellini ve ark. 1998).

Hindistan'da toprak kaynaklı hastalık ve zararlılardan korunmak amacıyla şeftaliler plastik serada farklı toprak içeriklerinde saksıda yetiştirilmiştir. Uygulamalar şeftalinin gelişimi üzerine önemli etkiler göstermiş ve en iyi sonuçlar toprak fumigasyonu + büyümeyi artıran bakteri $(250 \mathrm{ml})+$ biyolojik kontrol + önerilen süper fosfat'ın $\% 25$ uygulamasından elde edilmiştir (Thakur ve Sharma 2018).

Plastik serada yetişen 4 yaşındaki 'White Robin' şeftali çeşidine farklı kombinasyonlarda \%0.5'lik hidrojen siyanamid
(Dormex) ve \%1'lik sarımsak ekstrakı uygulanarak tomurcuk dinlenmesini kırma, meyve tutumu, verim ve meyve kalitesi üzerine etkileri 2 yıl süre ile araştırılmıştır. Tomurcuklarda dinlenmenin kırılması ve hasat periyodu kontrola göre Dormex uygulamasıyla 10 gün ve sarımsak ekstrakıyla 20 gün erkene alınmıştır. Örtüaltında yetiştiricilikteki bütün uygulamalar kontrole göre daha iyi sonuçlar vermiş ve Mısır koşullarında ihracata yönelik şeftali üretiminde örtüaltında yetiştiricilik yapılmasının gerekliliği vurgulanmıştır (Kotb ve ark. 2019).

Güney İspanya'da yetişen soğuklama ihtiyacı düşük 'Early Maycrest' şeftali çeşidine soğuklama ihtiyacinın $\% 50$ ve $\% 75$ oranında karşılandığ 1 aşamalarda Dormex ${ }^{\circledR}$ ve kışlık yağ uygulamaları yapılarak iki yıl süreyle çiçeklenme, hasat zamanı ve meyve tutum oranları araştırılmış̧ır. Soğuklama ihtiyacının hesaplanmasında soğuk birikimi $\left(7^{\circ} \mathrm{C}\right.$ 'nin altındaki sıcaklıklar, Utah model ve Dinamik model) kullanılmış ve aynı zamanda gölge ve güneşli olma durumu da dikkate alınmıştır. İki yılda arazi koşullarında saptanan soğuklama birikimi oldukça farklılık göstermiş ve uygulamalar kontrole göre hasadı 2007 yılında 2 gün 2008 yılında 3 gün öne alabilmiştir. Uygulamalar ve kontrol arasında çiçeklenme, hasada gelme ve meyve tutum oranları bakımından fark olmamıştır. Bundan dolayı oldukça düşük soğuklama ihtiyacı olan 'Early Maycrest' çeşidine ekstrem kış sıcaklıklarının yaşandığı yıllar haricinde uygulama yapılmamasının gerektiği vurgulanmıştır (Campoy ve ark. 2011).

'Florda Prince' şeftali çeşidine Brassinolide (Millagrow) ve Dormex uygulamaları çiçeklenmeyi ve meyve tutumunu kontrole göre 2 hafta öne almıştır. Yapraklarda en yüksek $\mathrm{N}$ ve $\mathrm{K}$ içeriği $\% 0.2$ brassinolide uygulamasından ve en yüksek meyve tutumu ile ürün miktarı $\% 0.5$ Dormex $+\% 0.2$ veya $\% 0.1$ brassinolide uygulamalarından elde edilmiştir. Ancak, uygulamalar meyve sertliğini azaltmıştır (Mohamed ve Hanaa 2015).

Antalya'da cam serada yetiştirilen 'Dixired', 'Early Red' ve 'Springtime' şeftali çeşitleri arasında sera içi ve sera dışında en erken meyve olumu 'Springtime' çeşidinde olmuş ve bunu sırasıyla 'Early Red' ve 'Dixired' çeşitleri takip etmiştir. Sera içindeki bitkiler dış ortamdakilerine göre 2 hafta önce hasada gelmişlerdir (Ertoy ve Ülger 2003).

$\mathrm{Bu}$ çalışmada; Antalya koşullarında erkencilik sağlamak için plastik serada saksı içerisinde yetiştirilen şeftalilere farklı uygulamalar yapılmıştır.

\section{Materyal ve metot}

\subsection{Materyal}

Araştırma 2010-2013 yılları arasında Akdeniz Üniversitesi Ziraat Fakültesi Araştırma ve Uygulama Arazisi ile Akdeniz Üniversitesi Tohumculuk Araştırma ve Geliştirme Merkezine bağlı plastik serada yürütülmüştür. Denemenin yürütüldüğü sera $51 \mathrm{~m}$ uzunluğunda, $18 \mathrm{~m}$ genişliğinde, $6 \mathrm{~m}$ mahya yüksekliğinde ve 3 tünelden oluşmaktadır. Sera $36^{\circ} 54028^{\prime}$ kuzey enleminde, $30^{\circ} 38810^{\prime}$ doğu boylamında ve denizden yüksekliği 38 m olan konumda bulunmaktadır.

Araştırmada ticari bir firmadan temin edilen şeftali çöğür anacı üzerine aşılı 'Early Maycrest', 'Francoise' ve 'Maycrest' şeftali çeşitleri kullanılmıştır. 


\subsection{Metot}

\subsubsection{Yetiştirme ortamı ve fidanlarda şekil oluşturma}

İçinde $\% 60$ torf $+\% 40$ organik gübre (koyun gübresi) karışımı bulunan 30 lt'lik saksılara dikilen 1 yaşındaki fidanlar goble şeklinde budanmıştır. Goble şeklinde taç oluşturmak için dikim sırasında fidanların tepesi $60 \mathrm{~cm}$ mesafeden vurularak, ilk $30 \mathrm{~cm}$ 'ye kadar olan sürgünler temizlenmiştir. Yaz ve kış budamalarıyla ağaç üzerinde $360^{\circ}$ ye eşit dağılmış ve birbiri arasında 5-10 cm mesafe olan 3-4 ana dal bırakılmıştır. Dal seçimi sonucunda tacın orta kısmı açık kalacak şekilde uygun bir goble şekli oluşturulmuştur. Daha sonra ana dallar üzerinde yardımcı dallar seçilerek, meyveye yatıncaya kadar yaz budamaları haziran ayı ortasında yapılmış ve budama sırasında ana dalların açısı 45-60 dereceye ayarlanmıştır.

Yetiştirme ortamının tuzluluk seviyesi 6.46 mmhos $\mathrm{cm}^{-1}$ (tuzlu), pH's1 7.43 (hafif alkali), kireç miktarı \%14.50 (fazla kireçli), organik madde düzeyi \%59.20 (yüksek seviyede), P, K, $\mathrm{Ca}, \mathrm{Fe}$ ve $\mathrm{Zn}$ seviyeleri çok yüksek, $\mathrm{Mg}$ seviyesi yüksek, $\mathrm{Cu}$ ile $\mathrm{Mn}$ seviyeleri ise orta seviyede olduğu toprak analiz sonuçlarına göre saptanmıştır.

Gübreleme programı, analiz sonuçları ve bitkinin içinde olduğu gelişme durumu dikkate alınarak hazırlanmıştır. Yetiştirme süresince bitkilerin bulunduğu her bir saksıya fertigasyon şeklinde mart, nisan, mayıs ve haziran ayları başında $30 \mathrm{~g} \mathrm{~N}: \mathrm{P}: \mathrm{K}(15: 15: 15)$ verilmiştir. Buna ilave olarak bitkilerde görülen kloroza karşı yapraktan Fe-EDTA sırt pompasıyla püskürtme şeklinde uygulanmıştır.

\subsubsection{Uygulamaların yapılması}

Fidanlara ocak ayı ortasında kontrol (saf su), \%2.5 Dormex (\%49 $\mathrm{H}_{2} \mathrm{CN}_{2}$, Agrikem), 200 ppm GA 3 (Merck) uygulamalar1 sırt pompasıyla püskürtme şeklinde fidanlar tamamen sslanacak şekilde yapılmış ve yayıcı yapıştırıcı olarak Tween (50 $\mathrm{ml} 100 \mathrm{~L}^{-1}$ ) kullanılmıştır. Soğukta bekletme uygulaması için ise fidanlar sıcaklığ $5^{\circ} \mathrm{C}^{\prime}$ ye ayarlanmış \%80-85 nem içeren soğuk hava deposuna taşınmış ve burada 30 gün bekletilmiştir. Uygulamalardan sonra fidanlar 15 Şubat tarihinde Akdeniz Üniversitesi Tohumculuk Araştırma ve Geliştirme Merkezine bağl1 $1000 \mathrm{~m}^{2}$ büyüklüğündeki plastik sera içerisine ve kontrol bitkileri ise sera dışına taşınmıştır. Bitkiler sera içerisine ve dış ortama $4 \times 3 \mathrm{~m}$ olacak şekilde dağıtılmıştır. Çiçeklenme zamanında tozlaşmayı artırmak amacıyla sera içerisine 2 kovan ve sera dışına 1 kovan bombus arısı yerleştirilmiştir. Bitkiler meyve hasadına kadar plastik serada tutulmuştur. Meyve hasadından sonra yaz aylarındaki sıcaklılardan korumak amacıyla sera içindeki ve dişındaki bitkiler \%40 1ş1k geçiren gölgelik altına taşınmıştır. Burada bir sonraki yıl yapılacak uygulamalara kadar bekletilmiş ve denemenin ikinci yılında da ilk yıldaki gibi aynı uygulamalar yapılmıştır.

\subsubsection{Fenolojik ve pomolojik parametrelerin saptanmast}

Araştırmada; \% uyanma (tomucukların kabarması), \% çiçeklenme başlangıcı (çiçeklerin \%5'nin açtığı dönem), \% tam çiçeklenme (çiçeklerin \%80'nin açtığı dönem), çiçeklenme sonu (çiçeklerin tamamının açtığı dönem), hasat zamanı (meyvelerin sertlik, renk ve tadını aldığı dönem), bitki başına verim $\left(\mathrm{g} \mathrm{bitki}^{-1}\right)$, yaprak dökümü (yaprakların tamamının döküldüğü dönem), meyve ağırlığı (g) meyve eni (mm), meyve boyu (mm), çekirdek ağırlığı (g), \% meyve eti çekirdek ağırlı̆̆ oranı, kabuk renk değişimi ( $\left.\mathrm{L}^{*}, \mathrm{C}^{*}, \mathrm{H}\right)$, meyve eti sertliği $\left(\mathrm{kg} \mathrm{cm} \mathrm{cm}^{-2}\right)$ belirlenmiştir. \% suda çözünebilir kuru madde miktarı (SÇKM)

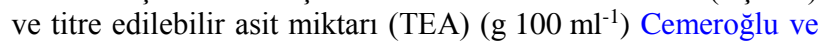
ark. (2007) göre saptanmıştır.

\subsubsection{Sonuçların değerlendirilmesi ve istatistiksel analizler}

Deneme deseni tesadüf blokları şeklinde 5 yinelemeli ve her yinelemede 1 adet bitki olacak şekilde kurulmuştur. Tüm istatistiksel analizler, SAS (versiyon 9.0) istatistik paket programında yapılmıştır. Pomolojik analizler 3 yinelemeli ve her yinelemede 4 meyve olacak şekilde "Tesadüf Parsellerinde Faktöriyel Düzen" deneme desenine göre gerçekleştirilmiş ve ortalamaların karşılaştırılmasında LSD testi kullanılmıştır.

\section{Bulgular}

\subsection{Fenolojik parametreler}

Her üç çeşitte de uygulamalar kontrole göre uyanmayı 1125 gün erkene almış ve erkene alma süresi çeşitlere ve uygulamalara göre değişim göstermiştir. Her üç çeşitte de en erken uyanmalar 25-26 Şubat tarihlerinde \%2.5 Dormex uygulanmış bitkilerde olmuş ve bunu sırasıyla 28 Şubat-1 Mart tarihleriyle 200 ppm $\mathrm{GA}_{3}$ ve 1-4 Mart tarihleriyle soğukta bekletme uygulamaları takip etmiştir (Çizelge 1).

Çizelge 1. Uygulamalar sonucu 'Early Maycrest', 'Francoise' ve 'Maycrest' şeftali çeşitlerinde saptanan ortalama bazı fenolojik parametreler ve verim değerleri.

Table 1. Average some phenological parameters and yield values determined in 'Early Maycrest', 'Francoise' and 'Maycrest' peach cultivars as a result of applications.

\begin{tabular}{|c|c|c|c|c|c|c|c|c|}
\hline Çeşit & Uygulama & Uyanma & Çiçek başlangıcı & Tam çiçek & Çiçeklenme sonu & Hasat & Verim $\left(\mathrm{g}\right.$ ağaç $\left.{ }^{-1}\right)$ & Yaprak dökümü \\
\hline \multirow[t]{4}{*}{ Early Maycrest } & Kontrol & 14 Mart & 21 Mart & 24 Mart & 27 Mart & 28 Mayis & $923.95^{\mathrm{f}^{*}}$ & 18 Aralık \\
\hline & $\% 2.5$ Dormex & 26 Şubat & 8 Mart & 11 Mart & 14 Mart & 18 Mayıs & $1638.40^{\mathrm{cd}}$ & 21 Aralık \\
\hline & $200 \mathrm{ppm} \mathrm{GA}_{3}$ & 1 Mart & 11 Mart & 13 Mart & 16 Mart & 18 Mayis & $1222.40^{\mathrm{e}}$ & 25 Aralık \\
\hline & Soğukta bekletme & 4 Mart & 14 Mart & 16 Mart & 19 Mart & 24 Mayıs & $1573.20^{\mathrm{d}}$ & 21 Aralık \\
\hline \multirow[t]{4}{*}{ Francois } & Kontrol & 17 Mart & 21 Mart & 23 Mart & 24 Mart & 22 Mayıs & $819.10^{\mathrm{fg}}$ & 22 Aralık \\
\hline & $\% 2.5$ Dormex & 25 Şubat & 5 Mart & 10 Mart & 11 Mart & 16 Mayis & $2305.05^{\mathrm{a}}$ & 18 Aralık \\
\hline & $200 \mathrm{ppm} \mathrm{GA}_{3}$ & 28 Şubat & 9 Mart & 13 Mart & 15 Mart & 14 Mayıs & $2301.15^{\mathrm{a}}$ & 21 Aralık \\
\hline & Soğukta bekletme & 1 Mart & 9 Mart & 13 Mart & 15 Mart & 18 Mayıs & $2120.80^{\mathrm{ab}}$ & 21 Aralık \\
\hline \multirow[t]{4}{*}{ Maycrest } & Kontrol & 15 Mart & 21 Mart & 23 Mart & 24 Mart & 29 Mayıs & $663.45^{\mathrm{h}}$ & 22 Aralık \\
\hline & $\% 2.5$ Dormex & 26 Şubat & 6 Mart & 10 Mart & 13 Mart & 24 Mayıs & $1862.50^{\mathrm{c}}$ & 20 Aralık \\
\hline & $200 \mathrm{ppm} \mathrm{GA}$ & 28 Şubat & 9 Mart & 11 Mart & 15 Mart & 26 Mayıs & $1631.15^{\mathrm{cd}}$ & 20 Aralık \\
\hline & Soğukta bekletme & 4 Mart & 11 Mart & 14 Mart & 17 Mart & 27 Mayıs & $2212.90^{\mathrm{a}}$ & 15 Aralık \\
\hline
\end{tabular}

*Uygulamalar arası fark önemli ( $\mathrm{P} \leq 0.05)$. 
Kontrole göre uyanmayı erkene alan uygulamalar ağaçların çiçeklenmelerine de yansımış ve çiçeklenmeye başlamayı 13-16 gün erkene çekmiştir. Her üç çeşitte de en erken çiçeklenme 5 Mart ('Francoise'), 6 Mart ('Maycrest') ve 8 Mart ('Early Maycrest') tarihlerinde \%2.5 Dormex uygulamasindan elde edilmiştir. 200 ppm GA3 uygulaması soğukta bekletmeye göre 'Early Maycrest' ve 'Maycrest' çeşitlerinde çiçeklenmeyi 2-3 gün öne almıştır. Her üç çeşidin kontrol bitkileri 21 Mart tarihinde çiçeklenmeye başlamışlardır. Uygulama yapılan ağaçlarda çiçeklenme 13 Mart ('Maycrest', \%2.5 Dormex) ile 19 Mart ('Earyl Maycrest', Soğukta bekletme) tarihlerinde sona ererken, 'Francoise' ve 'Maycrest' çeşitlerinin kontrol bitkilerinde 24 Mart ve 'Early Maycrest' çeşidinde ise 27 Mart tarihinde sona ermiştir (Çizelge 1).

Her üç uygulama şeftali çeşitlerinde hasadı kontrole göre 2 gün ('Maycrest', soğukta bekletme) ile 10 gün ('Early Maycrest', \%2.5 Dormex ve 200 ppm GA 3 ) erkene almıştır. İlk hasatlar 14 (200 ppm $\left.\mathrm{GA}_{3}\right)$ ve 16 Mayls (\%.2.5 Dormex) tarihlerinde 'Francoise' çeşidinde yapılırken bunu 16 Mayıs ile 'Francoise', 18 Mayıs ile 'Early Maycrest' (\%2.5Dormex ve 200 ppm GA 3 ) ve 'Francoise' (Soğukta bekletme) çeşitleri takip etmiştir. En geç hasat ise 29 Mayıs'ta 'Maycrest' çeşidinin kontrol bitkilerinde olmuştur (Çizelge 1).

Her üç çeşitte de uygulamalar verimi kontrole göre artırmıştır. Uygulamalar verimi en fazla verim 'Francois' çeşidinde artırırken, bunu sırasıyla 'Maycrest' ve 'Early Maycrest' çeşitleri takip etmiştir. Ortalama en fazla verim \%2.5 Dormex (2305 $\left.\mathrm{g}_{\text {ağaç }}{ }^{-1}\right)$ ve $200 \mathrm{ppm} \mathrm{GA}$ (2301 $\left.\mathrm{g}_{\text {ağaç }}{ }^{-1}\right)$ uygulanmış 'Francoise' ve soğukta bekletilmiş (2212 $\mathrm{g}$ ağaç-1) 'Maycrest' çeşitlerinden elde edilmiştir. Diğer uygulamalarda ortalama verim 1222 ile $2121 \mathrm{~g}_{\text {ağaç}}{ }^{-1}$ arasında değişmiştir. En düşük verimler sırasıyla $663.45,819.10$ ve $923.95 \mathrm{~g}_{\text {ağaç}}{ }^{-1}$ ile 'Maycrest', 'Francoise' ve 'Early Maycrest' çeşitlerinin kontrol bitkilerinde olmuştur (Çizelge 1).

Çeşitlerdeki ortalama yaprak döküm tarihleri 15 Aralık ('Maycrest', Soğukta bekletme) ve 25 Aralık ('Early Maycrest', $200 \mathrm{ppm} \mathrm{GA}$ ) arasında olmuştur. Uygulamalar sonucu sadece 'Early Maycrest' çeşidinde kontrole göre birkaç gün geç yaprak dökümü olurken, 'Francoise' ve 'Maycrest' çeşitlerinde ise birkaç gün daha erken yaprak dökümü gerçekleşmiştir (Çizelge $1)$.

Çizelge 2. Uygulamalar sonucu 'Early Maycrest', 'Francoise' ve 'Maycrest' şeftali çeşitlerinde saptanan ortalama bazı pomolojik sonuçlar.

Table 2. Average some pomological results detected in 'Early Maycrest', 'Francoise' and 'Maycrest' peach cultivars as a result of applications.

\begin{tabular}{|c|c|c|c|c|c|c|c|c|}
\hline Çeşit & Uygulama & $\begin{array}{l}\text { Meyve ağırlığı } \\
(\mathrm{g})\end{array}$ & $\begin{array}{c}\text { Meyve eni } \\
(\mathrm{mm})\end{array}$ & $\begin{array}{c}\text { Meyve boyu } \\
(\mathrm{mm})\end{array}$ & $\begin{array}{l}\text { Çekirdek ağırlı̆̆ } 1 \\
(\mathrm{~g})\end{array}$ & Meyve eti çekirdek oranı & $\begin{array}{c}\text { SÇKM } \\
(\%)\end{array}$ & $\begin{array}{c}\text { TEA } \\
\left(\mathrm{g} 100 \mathrm{mg}^{-1}\right)\end{array}$ \\
\hline \multirow[t]{4}{*}{ Early Maycrest } & Kontrol & $51.31^{\mathrm{j}}$ & $27.09^{\mathrm{e}}$ & $28.79^{\mathrm{e}}$ & $2.34^{\mathrm{e}}$ & $9.77^{\mathrm{f}}$ & $12.06^{\mathrm{b}}$ & $0.50^{\text {cd }}$ \\
\hline & $\% 2.5$ Dormex & $87.58^{\mathrm{e}}$ & $52.70^{\mathrm{c}}$ & $56.30^{\mathrm{b}}$ & $4.20^{\mathrm{b}}$ & $20.39^{\mathrm{cd}}$ & $13.14^{\mathrm{a}}$ & $0.55^{\mathrm{c}}$ \\
\hline & $200 \mathrm{ppm} \mathrm{GA}_{3}$ & $76.44^{\mathrm{g}}$ & $52.27^{\mathrm{c}}$ & $56.01^{\mathrm{b}}$ & $3.30^{\mathrm{c}}$ & $23.09^{c}$ & $12.36^{\mathrm{b}}$ & $0.51^{\mathrm{cd}}$ \\
\hline & Soğukta bekletme & $94.19^{\mathrm{d}}$ & $51.45^{\mathrm{c}}$ & $56.25^{\mathrm{b}}$ & $3.27^{\mathrm{c}}$ & $29.29^{\mathrm{a}}$ & $12.77^{\mathrm{ab}}$ & $0.56^{\mathrm{c}}$ \\
\hline \multirow[t]{4}{*}{ Francois } & Kontrol & $66.77^{\mathrm{h}}$ & $49.61^{\mathrm{cd}}$ & $48.74^{\mathrm{c}}$ & $3.12^{\mathrm{cd}}$ & $22.01^{\mathrm{c}}$ & $11.03^{\mathrm{cd}}$ & $0.39^{\mathrm{e}}$ \\
\hline & $\% 2.5$ Dormex & $96.29^{\mathrm{d}}$ & $55.50^{\mathrm{b}}$ & $62.29^{\mathrm{a}}$ & $3.58^{\mathrm{c}}$ & $27.65^{\mathrm{ab}}$ & $11.86^{\mathrm{bc}}$ & $0.67^{\mathrm{b}}$ \\
\hline & 200 ppm GA 3 & $115.89^{\mathrm{a}}$ & $55.47^{\mathrm{b}}$ & $61.73^{\mathrm{a}}$ & $4.25^{\mathrm{b}}$ & $26.33^{\mathrm{b}}$ & $11.66^{\mathrm{c}}$ & $0.67^{\mathrm{b}}$ \\
\hline & Soğukta bekletme & $103.87^{\mathrm{c}}$ & $53.52^{\mathrm{bc}}$ & $60.79^{\mathrm{a}}$ & $5.33^{\mathrm{a}}$ & $18.83^{\mathrm{d}}$ & $10.92^{\mathrm{cd}}$ & $0.80^{\mathrm{a}}$ \\
\hline \multirow[t]{4}{*}{ Maycrest } & Kontrol & $58.78^{1}$ & $45.73^{\mathrm{d}}$ & $43.10^{\mathrm{d}}$ & $3.36^{\mathrm{c}}$ & $14.08^{\mathrm{e}}$ & $10.66^{\mathrm{d}}$ & $0.56^{\mathrm{c}}$ \\
\hline & $\% 2.5$ Dormex & $112.05^{\mathrm{ab}}$ & $60.51^{\mathrm{a}}$ & $57.18^{\mathrm{b}}$ & $5.41^{\mathrm{a}}$ & $19.81^{\mathrm{d}}$ & $11.91^{\mathrm{bc}}$ & $0.66^{\mathrm{b}}$ \\
\hline & $200 \mathrm{ppm} \mathrm{GA}_{3}$ & $82.08^{f}$ & $53.74^{\mathrm{bc}}$ & $55.57^{\mathrm{b}}$ & $4.38^{\mathrm{b}}$ & $17.99^{\mathrm{d}}$ & $11.69^{c}$ & $0.56^{\mathrm{c}}$ \\
\hline & Soğukta bekletme & $106.66^{\mathrm{b}}$ & $59.64^{\mathrm{a}}$ & $57.36^{\mathrm{b}}$ & $5.55^{\mathrm{a}}$ & $19.19^{\mathrm{d}}$ & $13.15^{\mathrm{a}}$ & $0.77^{\mathrm{a}}$ \\
\hline
\end{tabular}

* Uygulamalar arası fark önemli $(\mathrm{P} \leq 0.05)$.

\subsection{Pomolojik analizler}

Uygulamalar kontrole göre meyve ağırlı̆̆ı, meyve boyu, meyve eni, çekirdek ağırlığı ve meyve eti çekirdek oranını artırmış, ancak SÇKM ve TEA üzerine önemli etki etmemiştir (Çizelge 2).

En fazla meyve ağırlı̆g $115.89 \mathrm{~g}$ ile $200 \mathrm{ppm} \mathrm{GA}_{3}$ uygulanmış 'Francoise' çeşidinde olurken bunu sırasılyla $112.05 \mathrm{~g}$ ile $\% 2.5$ Dormex ve $106.66 \mathrm{~g}$ ile soğukta bekletilmiş 'Maycrest' çeşidi takip etmiştir. Kontrol bitkilerinde en ağır meyveler $66.71 \mathrm{~g}$ ile 'Francoise'de ve en düşük ise $51.31 \mathrm{~g}$ ile 'Early Maycrest' çeşitlerinde saptanmıştır. Meyve ağırlı̆̆ını 'Early Maycrest' çeşidinde soğukta bekletme (94.19 g) en fazla artırırken, 'Francoise'de 200 ppm GA 3 (115.89 g) ve 'Maycrest'de ise \%2.5 Dormex (112.05 g) artırmıştır (Çizelge 2).

Kontrole göre en fazla meyve eni artış1 'Maycrest' çeşidinde olmuş ve bunu 'Francoise' ve 'Early Maycrest' çeşitleri takip etmiştir. En fazla meyve eni $60.51 \mathrm{~mm}$ ile \% 2.5 Dormex uygulanmış 'Maycrest' çeşidinde ve en düşük ise 27.09 $\mathrm{mm}$ ile 'Early Maycrest' çeşidinin kontrol bitkilerinde ölçülmüştür. Uygulamalar şeftali çeşitlerinde ('Maycrest' 200 ppm $\mathrm{GA}_{3}$ hariç) meyve enlerini çok fazla değiştirmemiş ve meyve enleri birbirlerine yakın olmuştur (Çizelge 2).

'Francoise' çeşidinde meyve boyları 60.79-62.29 mm, 'Maycrest'de 57.36-57.57 mm ve 'Early Maycrest'de 56.01$56.30 \mathrm{~mm}$ arasında değişmiştir. Uygulamalar kontrole göre meyve boyunu artırmış ancak uygulamalar arasında çok fazla farklılık olmamıştır. Kontrol bitkilerinde en fazla meyve boyu $48.79 \mathrm{~mm}$ ile 'Francoise' çeşidinde belirlenmiş ve bunu 43.10 mm ile 'Maycrest' ve $28.79 \mathrm{~mm}$ ile 'Early Maycrest' çeşidi takip etmiştir (Çizelge 2).

Uygulamalar arasında en iri çekirdekler soğukta bekletilmiş 'Maycrest' ve 'Francoise' çeşitlerinden sırasıyla 5.55 ve $5.33 \mathrm{~g}$ olarak elde edilmiştir. En fazla çekirdek ağırlığı 'Maycrest' çeşidinde olurken, 'Francoise' ve 'Early Maycrest' çeşitleri bunu takip etmiştir. Kontrol bitkilerinde en ağır çekirdek $3.36 \mathrm{~g}$ ile 'Maycrest' ve en düşük ise $2.34 \mathrm{~g}$ ile 'Early Maycrest' çeşidinde tartılmıştır (Çizelge 2). 
En fazla meyve eti çekirdek oranı 29.29 ile soğukta bekletilmiş 'Early Maycrest' çeşidinde saptanmış ve bunu surasiyla 27.65 ile \%2.5 Dormex ve 26.33 ile 200 ppm $\mathrm{GA}_{3}$ uygulanan 'Francoise' çeşidi takip etmiştir. Uygulamalar 'Maycrest' çeşidinde meyve eti çekirdek ağırlığı oranını fazla değiştirmemiş ve değerler 17.99-19.81 arasında değişmiştir. Kontrol bitkilerinde en yüksek meyve eti çekirdek oranı 22.01 ile 'Francoise' ve en düşük ise 9.77 ile 'Early Maycrest' çeşitlerinde belirlenmiştir (Çizelge 2).

En fazla SÇKM \%13.15 ve \%13.14 ile sırasıyla soğukta bekletilen 'Maycrest' ve \%2.5 Dormex uygulanan 'Early Maycrest' çeşitlerinde ölçülmüştür. Uygulamalar 'Francoise' ve 'Early Maycrest (\%2.5 Dormex hariç)' çeşitlerinde kontrole göre SÇKM miktarını çok fazla değiştirmemiş, ancak 'Maycrest' çeşidinde değişim önemli olmuştur. Kontrol bitkilerinde en fazla SÇKM \%12.06 ile 'Early Maycrest' çeşidinde olurken bunu sırasıyla \%11.03 ile 'Francoise' ve $\% 10.66$ ile 'Maycrest' takip etmiştir (Çizelge 2).

Uygulamalar TEA miktarını kontrole göre 'Early Maycrest' çeşidinde önemli oranda değiştirmezken, 'Francoise' ve 'Maycrest' çeşitlerinde önemli oranda değiştirmiştir. En fazla

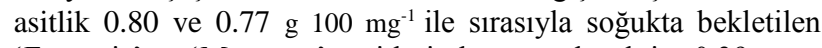
'Francois' ve 'Maycrest' çeşitlerinde ve en düşük ise $0.39 \mathrm{~g} 100$ $\mathrm{mg}^{-1}$ ile 'Francois' çeşidinin kontrol bitkilerinde saptanmıştır (Çizelge 2).

\subsection{Meyve kabuk rengi}

Uygulamalar kontrole göre meyve kabuğu parlaklığını sadece 'Early Maycrest' çeşidinde artırmış ve en parlak meyveler 200 ppm GA $\mathrm{G}_{3}$ uygulanan 'Early Maycrest' çeşidinde saptanmıştır. 'Francoise' çeşidinde meyve kabuğu parlaklığ kontrole göre çok fazla değişmemiştir. 'Maycrest' çeşidinde ise soğukta bekletme ve \%2.5 Dormex uygulamaları meyve kabuğu parlaklığını kontrole göre azaltmıştır (Çizelge 3).

Uygulamalar sadece 'Early Maycrest' çeşidinde meyve kabuğu canlılı̆ğnı biraz artırırken, 'Francoise' ve 'Maycrest' çeşitlerinde azaltmıştır. Meyve kabuğunda en yüksek canlılık 'Maycrest' çeşidinin kontrol ve en düşük ise \%2.5 Dormex uygulanan 'Francoise' çeşidinde belirlenmiştir (Çizelge 3).

Uygulamalar kontrole göre 'Francoise' ve 'Maycrest' çeşitlerinde meyvenin kırmızılaşmasını artırmış, ancak 'Early Maycrest' çeşidinde soğukta bekletme hariç azaltmıştır. En fazla kırmızı renklenme soğukta bekletilen ve \%2.5 Dormex uygulanan 'Francoise' çeşidinde saptanmıştır. Soğukta bekletilen bitkilerin meyvelerinin kırmızılaşması diğerlerine göre daha fazla olmuştur (Çizelge 3).

\section{Tartışma ve Sonuç}

Türkiye, Akdeniz ülkeleri içerisinde şeftali üretimi bakımından son yıllarda büyük ilerlemeler kaydetmiş ve Çanakkale'de 1lıman, Adana, Antalya, Hatay ve Mersin'de subtropik ve Bursa ile Erzincan gibi yayla iklim kuşaklarında yetiştiriciliği yaygınlık kazanmıştır (Baş ve ark. 2000). Akdeniz sahil şeridinde sert çekirdekli meyvelerin turfanda yetiştiriciliği üreticiler açısından çok önemlidir. Akdeniz sahil bölgesinde soğuklama ihtiyacı az olan erkenci şeftali çeşitlerinin yetiştirilmesi durumunda, mayıs ayından itibaren ürünün pazara sunulabilmesi mümkün olabilmekte ve üreticiler önemli kazançlar elde edebilmektedirler (Özçağıran 1999; Kuden ve ark. 2004). Turfanda yetiştiriciliği daha da erkene alabilmek amacıyla şeftalilerin örtüaltında toprağa dikili veya saksıda yetiştiriciliği üzerinde yapılan çalışmalarda önemli sonuçlar elde edilmiş ve diş ortamda yetiştiriciliğe göre 7-14 gün arasında değişen erkencilik sağlanmıştır (Fuss ve ark. 1990; Erez ve ark. 1993).

Çizelge 3. Uygulamalar sonucu 'Early Maycrest', 'Francoise' ve 'Maycrest' şeftali çeşitlerinde saptanan ortalama meyve kabuk rengi değerleri.

Table 3. Average fruit shell color values determined in 'Early Maycrest', 'Francoise' and 'Maycrest' peach cultivars as a result of applications.

\begin{tabular}{|c|c|c|c|c|}
\hline Çeşit & Uygulama & $\mathrm{L}^{*}$ & $\mathrm{C}^{*}$ & $\mathrm{H}$ \\
\hline \multirow{4}{*}{ Early Maycrest } & Kontrol & $35.71^{\mathrm{h}}$ & $33.79^{\mathrm{d}}$ & $39.79^{\mathrm{e}}$ \\
\hline & $\% 2.5$ Dormex & $49.16^{\mathrm{b}}$ & $36.98^{\mathrm{b}}$ & $44.37^{\mathrm{c}}$ \\
\hline & $200 \mathrm{ppm} \mathrm{GA} 3$ & $52.60^{\mathrm{a}}$ & $35.12^{\mathrm{c}}$ & $43.90^{c}$ \\
\hline & Soğukta bekletme & $47.03^{\mathrm{c}}$ & $34.33^{\mathrm{cd}}$ & $39.70^{\mathrm{e}}$ \\
\hline \multirow[t]{4}{*}{ Francois } & Kontrol & $40.40^{\mathrm{f}}$ & $36.43^{b}$ & $42.02^{\mathrm{d}}$ \\
\hline & $\% 2.5$ Dormex & $39.58^{\mathrm{fg}}$ & $28.81^{\mathrm{fg}}$ & $32.27^{\mathrm{h} \text { t }}$ \\
\hline & $200 \mathrm{ppm} \mathrm{GA}_{3}$ & $40.65^{\text {ef }}$ & $33.82^{\mathrm{d}}$ & $38.10^{\mathrm{f}}$ \\
\hline & Soğukta bekletme & $41.48^{\mathrm{e}}$ & $29.12^{\mathrm{f}}$ & $33.24^{\mathrm{h}}$ \\
\hline \multirow[t]{4}{*}{ Maycrest } & Kontrol & $47.27^{\mathrm{bc}}$ & $40.46^{\mathrm{a}}$ & $48.79^{\mathrm{a}}$ \\
\hline & $\% 2.5$ Dormex & $44.49^{\mathrm{d}}$ & $35.44^{\mathrm{bc}}$ & $34.45^{\mathrm{g}}$ \\
\hline & 200 ppm GA 3 & $49.64^{\mathrm{b}}$ & $35.76^{\mathrm{bc}}$ & $47.50^{\mathrm{b}}$ \\
\hline & Soğukta bekletme & $42.78^{\mathrm{de}}$ & $31.31^{\mathrm{e}}$ & $35.28^{\mathrm{g}}$ \\
\hline
\end{tabular}

Antalya'da cam serada saksıda yetiştirilen 'Dixired', 'Early Red' ve 'Springtime' şeftali çeşitleri dış ortamdakilerine göre 14 gün önce (mayıs başı) hasada gelmişlerdir (Ertoy ve Ülger 2003), ancak araştırmada ise saksıda yetişen şeftaliler plastik serada hasada dış ortama göre 2-10 gün erken (14 Mayıs) gelmişlerdir. Açıkta Çukurova yöresinde 'GF677' anacı üzerine aş1l 'Francoise' ve 'Maycrest' şeftali çeşitleri 10 Mayıs'ta (Türkmen 2003) ve Adana koşullarında ise 'GF-677' anacı üzerine aş11 'Early Maycrest' ve 'Francoise' şeftali çeşitleri 12 Mayıs'ta (Emerce 2004) hasat edilmişlerdir. Buna karşın, dış ortama göre plastik serada Misır'da 15 Mart'ta (Kotb ve ark. 2019), Sicilya'da nisan sonunda (Bellini ve ark. 1992) ve İsrail'de mart sonunda (Erez ve ark. 1998) şeftali hasadı yapılabilmektedir. Sonuçlar rakım, çeşit, anaç, yetişme ortamı ve yetiştiği bölgenin iklim koşullarının şeftalinin hasada gelmesini nasıl etkilediğini açıç̧a göstermektedir. Bu durum, ülkemizde ihracata yönelik şeftali üretimi yapacak olanların mutlaka üretim planlamasını rakip ülkelere ayarlaması gerekliliğini açıkça ortaya çıkarmaktadır.

$\mathrm{GA}_{3}$ ve \%2.5 Dormex uygulamaları şeftali, erik ve kayısı çeşitlerinin erken uyanmasını sağlamaktadır (Westwood 1993; Shulman ve ark. 1986; Mohamed 2008; Leonel ve Tecchio 2011; Campoy ve ark. 2011; Mohamed ve Hanaa 2015; Karakurum 2016). Bu sonuçları destekleyecek şekilde çalışmada da \%2.5 Dormex ve $\mathrm{GA}_{3}$ uygulamaları kontrole göre uyanmayı 11-25 gün erkene almıştır. Erken uyanma ağaçların çiçeklenmelerine de yansımış ve çiçeklenme 13-16 gün erken olmuştur. Ancak en erken uyanma ve çiçeklenme \%2.5 Dormex uygulamalarında olmasına karşın en erken meyve olgunlaşmasının 200 ppm GA3 uygulamasından elde edilmesi, erken çiçeklenme ile meyvenin erken olgunlaşması arasında doğrusal ilişkinin olmadığını göstermektedir. Benzer sonuçları Ertoy ve Ülger (2003) ve Kotb ve ark. (2019)'da elde etmişlerdir. Diğer yandan çeşitlerdeki yaprak döküm tarihleri arasında çok önemli farkın olmaması \%2.5 Dormex, $\mathrm{GA}_{3}$ ve soğukta bekletme uygulamalarının erken uyanmayı teşvik etmelerine rağmen yaprak dökümü üzerine etkili olmadıklarını ortaya çıkarmışır. 
Örtüaltında ve açıkta yetişen şeftalilerin soğuklama ihtiyacını karşılayamaması yetiştiricilikte karşılaşılan önemli bir sorundur. Soğuklama ihtiyacını karşılamak amacıyla $\mathrm{KNO}_{3}$, thiourea, \%2.5 Dormex, dinitro bileşenleri (DNC) ve dinitro orto kresol (DNOC) (Fuss ve ark. 1990; Leonel ve Tecchio 2011; Campoy ve ark. 2011) gibi kimyasalların uygulanmasının yanı sıra, yüksek rakımlı yerlere taşımak, yaz aylarında üstten yağmurlama yapmak ve soğuk hava deposunda bekletme (Erez ve ark. 1993) gibi uygulamalar da yapılmaktadir. Uygulamaların etkisi çeşide, iklime, açıta ve örtüaltında yetiştirilmesine göre değişmektedir.

Soğuklama ihtiyacını gidermek, erken uyanma ve çiçeklenmeyi sağlamak amacıyla uygulanan kimyasallar aynı zamanda şeftalilerde verim artışına neden olmaktadır (Erez ve ark. 1993; Falqui ve ark. 1994; Ertoy ve Ülger 2003; Leonel ve Tecchio 2011). Araştırmada kontrole göre en fazla verim artış1 $\% 2.5$ Dormex uygulamasinda elde edilirken bunu sirasiyla 200 ppm $\mathrm{GA}_{3}$ ve soğukta bekletme takip etmesi \%2.5 Dormex uygulamasının şeftalide verimi daha fazla artırabileceğini göstermektedir.

Araştırma sonuçları \%2.5 Dormex, $\mathrm{GA}_{3}$ ve soğukta bekletme uygulamalarının aynı zamanda meyvelerin ağırlığını, boyunu, enini, çekirdek ağırlığını ve meyve eti çekirdek oranını da artırdığını; ancak SÇKM ve TEA üzerine önemli etki etmediğini ortaya çıkarmıştır. Ayrıca, düşük asit içeren meyvelerin SÇKM içeriklerinin yüksek olmaması, düşük asitlik ile yüksek SÇKM arasında doğrusal bir ilişki olmayabileceğini göstermektedir.

$\mathrm{GA}_{3}, \% 2.5$ Dormex ve soğukta bekletme uygulamalarının kontrole göre meyve kabuğu canlılığ çeşitlerde artırırken bazılarında azaltması, uygulamaların etkisinin çeşide göre değiştiğini göstermektedir. Ancak uygulamaların çoğunun kontrole göre kırmızı rengi artırması, uygulamaların renklenme üzerine olumlu etki yapabileceğini de göstermektedir.

Araştırma sonuçları, Antalya koşullarında plastik serada saksıda şeftali yetiştiriciliğinin yapılmasında bir sorunla karşılaşılmayacağı ve $\mathrm{GA}_{3}$ ve \%2.5 Dormex uygulamalarının dış ortama göre çeşide bağlı olarak 2-10 günlük bir erkencilik sağlayabileceğini göstermiştir. Ayrıca, \%2.5 Dormex uygulamasının erkencilik ve verim bakımından daha iyi sonuçlar vermesi, soğuklama ihtiyacını karşılamak için fidanların soğuk hava depolarında bekletmenin gerekli olmadığını ortaya çıkarmıştır. Çünkü soğuk havada bekletme uygulamasında saksı içindeki fidanları taşımak zor olmakta ve ilave elektrik parası ödenmektedir. Ancak, sonuçların iki yıllık olmas1 nedeniyle uzun sürede hangi uygulamanın daha iyi olabileceği fikri tam sonuca kavuşmuş değildir.

\section{Teşekkür}

$\mathrm{Bu}$ eser Doktora çalışmasının bir kısmıdır ve 2010.03.0121.013 nolu proje ile Akdeniz Üniversitesi Bilimsel Araştırma Projeleri Koordinasyon Birimi'nce desteklenmiştir.

\section{Kaynaklar}

Baş M, Öztürk M, Ufuk S (2000) Sert Çekirdekli Meyveler. Şeftali raporu. Bitkisel Üretim Özel İhtisas Komisyonu. D.P.T. Raporu VIII. 5 Yıllık Kalkınma Planı, Yalova.

Bellini E, Falqui D, Musso O (1992) Protected peach culture in Sicily. Six years of research on training systems and pruning methods. $\begin{array}{llll}\text { Acta Horticulturae } & \text { 315: } & \end{array}$ 10.17660/ActaHortic.1992.315.6.
Bellini E, Falqui D, Musso O (1998) Comparative evaluation of peach and nectarine cultivars trained to permanent canopy in protected culture in Sicily Acta Horticulturae 513: 435-442. doi: 10.17660/ActaHortic.1998.513.52.

Campoy JA, Ruiz D, Egea J (2011) Suitability of hydrogen cyanamide plus oil application for dormancy overcoming in 'Early Maycrest' peach in a warm-winter climate. European Journal of Horticultural Science 76(2): 51-55.

Cemeroğlu B, Yemencioğlu A, Özhan M (2007) Gıda Analizleri Kitabı, Ankara, s. 45-88.

Emerce O (2004) Bazı 1lıman iklim meyve tür ve çeşitlerinin subtropik koşullardaki performansları. Yüksek Lisans Tezi, Çukurova Üniversitesi Fen Bilimleri Enstitüsü, Adana.

Erez A, Nir G, Lerner H, Yablowitz Z (1993) Container grown peach trees: Evaluation of a commercial endeavor. Acta Horticulturae 349: 43-47. doi: 10.17660/ActaHortic.1993.349.5.

Erez A, Yablowitz Z, Korcinski R (1998) Greenhouse peach growing. Acta Horticulturae 465: 593-600. doi: 10.17660/ActaHortic.1998.465.74.

Erez A, Yablowitz Z, Korcinski R (2000) Temperature and chemical effects on competing sinks in peach bud break. Acta Horticulturae 514: 51-58. doi: 10.17660/ActaHortic.2000.514.5.

Ertoy N, Ülger S (2003) Antalya'da cam serada erkenci şeftali yetiştirme olanaklarının araştırılması. Türkiye IV. Ulusal Bahçe Bitkileri Kongresi, Cilt 1, Antalya, s. 26-28.

Falqui D, Lovicu G, Pala M (1994) High density protected culture of peaches: A three year research study on permanent canopy cultivation in Sardinia. Acta Horticulturae 361: 565-573.

Fuss AM, Burne PM, Coombe BG, Sedgley M (1990) Cultural manipulation for out-of-season peach production under glass. Scientia Horticulturae 43: 15-27.

Karakurum E (2016) Örtüaltında yetiştirilen erik ve kayısı çeşitlerinde hidrojen siyanamid $\left(\mathrm{H}_{2} \mathrm{CN}_{2}\right)$ uygulamasının erkencilik ve verim üzerine etkileri. Yüksek lisans Tezi, Adnan Menderes Üniversitesi Fen Bilimleri Enstitüsü, Aydın.

Kotb HRM, El-Abd MAM, Salama A (2019) Response of "White Robin" peach trees Cv. (Prunus persica L.) to cultivation under plastic covering conditions and foliar application by hydrogen cyanamide and garlic extract. Journal of Plant Production 10(12): 1187-1194. doi: 10.21608/JPP.2019.87395.

Kuden A, Kuden AB, Turkmen O, Ozguven AI, Rehber Y, Sayginer E, Imrak B (2004) Peach, nectarine and plum growing possibilities under subtropical conditions of Turkey and North Cyprus. Acta Horticulturae 662: 119-126.

Leonel S, Tecchio MA (2011) Yield and harvest period of peach and nectarine cultivars at free blooming and with the use of hydrogen cyanamide. Revista Brasileira de Fruticultura 33(1): 227-234.

Mohamed AKA (2008) The effect of chilling, defoliation and hydrogen cyanamide on dormancy release, bud break and fruiting of Anna apple cultivar. Scientia Horticulturae 118(4): 351-352.

Mohamed SA, Hanaa MS (2015) Enhancing the performance of "Florda Prince" peach cultivar with growth promoter "brassinolide" and break agent "hydrogen cyanamide". Journal of Horticultural Science \& Ornamental Plants 7(1): 39-47. doi: 10.5829/idosi.jhsop.2015.7.1.1154.

Özçağıran R (1999) Ilıman İklim Meyve Türleri Ders Notları. Ege Üniversitesi Ziraat Fakültesi Bahçe Bitkileri Bölümü, İzmir.

Shulman Y, Nir G, Lavee S (1986) Oxidative processes in bud dormancy and the use of hydrogen cyanamide in breaking dormancy. Acta Horticulturae 179: 141-148.

Thakur KM, Sharma DP (2018) Pot-culture studies on soil and leaf nutrients status of peach in response to different soil management techniques for preventing replant disease. The Pharma Innovation Journal 7(4): 1046-1053. 
Türkmen Ö (2003) Bazı yeni șeftali ve nektarin çesitlerinin Cukurova koşullarındaki performanslarının incelenmesi. Yüksek Lisans Tezi, Çukurova Üniversitesi Fen Bilimleri Enstitüsü, Adana.
Westwood MN (1993) Hormones and Growth Regulators. Temperate Zone Pomology: Physiology and Culture. Timber Press, Inc. 9999 S.W. Wilshire, Suite 124, Portland, Oregon 97225. 